\title{
ARTICLE
}

Cite this: DOI: $10.1039 / \times 0 \times x 00000 x$

\section{Directional Synthesis of Tin Oxide@Graphene Nanocomposites via a One-Step Up-scalable Wet- mechanochemical Route for Lithium ion Batteries}

Received 00th January 2012, Accepted 00th January 2012

DOI: 10.1039/x0xx00000x

www.rsc.org/

\author{
Sheng $\mathrm{Li}^{\mathrm{a}}$, Yazhou Wang ${ }^{\mathrm{a}}$, Chao Lai ${ }^{\mathrm{a}}$, Jingxia Qiu ${ }^{\mathrm{a}}$, Min Ling ${ }^{\mathrm{a}}$, Wayde Martens ${ }^{\mathrm{b}}$, \\ Huijun Zhao and Shanqing Zhang ${ }^{\mathrm{a} *}$
}

\begin{abstract}
Directional synthesis of $\mathrm{SnO}_{2} @$ graphene nanocomposites via a one-step, low-cost, and upscalable wet-mechanochemical method is achieved using graphene oxide and $\mathrm{SnCl}_{2}$ as precursors. The graphene oxides are reduced to graphene while the $\mathrm{SnCl}_{2}$ is oxidized to $\mathrm{SnO}_{2}$ nanoparticles that are in-situ anchored onto the graphene sheets evenly and densely, resulting in uniform $\mathrm{SnO}_{2} @$ graphene nanocomposites. The prepared nano-composites possess excellent electrochemical performance and outstanding cycling in Li-ion batteries.
\end{abstract}

\section{Introduction}

Lithium-ion batteries (LIBs) are the most encouraging power sources for the electrical vehicles (EVs) because of their high energy density, high voltage, light weight and non-memory effect. ${ }^{1,2}$ To date, on one hand, there are abundant high specific capacity electrode materials (such as $\mathrm{SnO}_{2}$ and $\mathrm{Si}$ ); on the other hand, it still lacks of a low cost, up-scalable manufacturing process to produce low cost and highly stable electrode materials for LIBs. As a consequence, even though graphite has a limited theoretical capacity of $372 \mathrm{mAh} \mathrm{g}^{-1}$, it is the most widely used anode materials available in current market. ${ }^{3,4}$ In order to overcome this barrier, facile production process of anode materials with superior performance, in terms of energy capacity, current density and cycling stability, is in high demand for the EVs and energy storage industries.

Tin dioxide $\left(\mathrm{SnO}_{2}\right)$ has substantial potential to replace graphite anodes and address this problem due to its significantly higher theoretical reversible Li-ion storage capacity $\left.\left(782 \mathrm{mAh} \mathrm{g}^{-1}\right)\right)^{5-8}$ The electrochemical processes of Li-ion storage can be commonly summarized as a two-step reaction: ${ }^{-11}$

$\mathrm{SnO}_{2}+4 \mathrm{Li}^{+}+4 \mathrm{e}^{-} \rightarrow \mathrm{Sn}+2 \mathrm{Li}_{2} \mathrm{O}$

$\mathrm{Sn}+x \mathrm{Li}^{+}+x \mathrm{e}^{-} \leftrightarrow \mathrm{Li}_{x} \mathrm{Sn}(0 \leq x \leq 4.4)$

It is well-established that the reaction depicted in Equation (1), is normally irreversible, but could become reversible when $\mathrm{SnO}_{2}$ particles reach nanoscale ${ }^{10,12}$. The theoretical reversible capacity is hence commonly calculated from Equation (2). However, like other alloyed compounds, deficiencies in the charge/discharge process, such as volume expansion and contraction (up to 300\%) would lead to poor cycle performance and would hamper $\mathrm{SnO}_{2}$ from practical application. ${ }^{13}$ The maintenance of particle size and electrical conductivity of the $\mathrm{SnO}_{2}$ is beneficial to the achievement of high rate capacity as well as the cycle stability of $\mathrm{SnO}_{2}$-based LIBs. Different approaches have been proposed for the preparation of nanostructured or hierarchical nano-structured $\mathrm{SnO}_{2}$ composites to overcome the obstacles and to allow the production of $\mathrm{SnO}_{2}$-based LIBs. ${ }^{14-19}$ Although significant improvements in the electrochemical performances and stability have been achieved, these designs are often sophisticated, and hence have the associated problems of low production yield and high cost.

Anchoring the $\mathrm{SnO}_{2}$ nanoparticles onto the graphene sheets could be an excellent strategy to resolve these problems due to the inherent advantages of graphene, such as its exceptionally large specific surface area, excellent conductivity, outstanding mechanical flexibility and pronounced chemical stability. ${ }^{20-22}$ More importantly, with the correct synthesis technique, $\mathrm{SnO}_{2}$ and hence the resultant $\mathrm{Sn}$ nanoparticles, could be firmly immobilized on graphene sheets. This brings numerous benefits: the electrons resulting from the alloying and de-alloying processes could be readily collected by copper current collectors via the graphene; the aggregation of the $\mathrm{SnO}_{2}$ nanoparticles and the restacking of graphene sheets could be effectively prevented. Importantly, the $\mathrm{SnO}_{2}$ particles will be anchoring on graphene layers thus the collapse of the electrode material due to the volume changing during charge/discharge process could be avoided largely. Therefore, well synthesized graphene composites could provide a high and stable cycling performance for LIBs.

Mechanochemical synthesis (i.e., ball-milling or grinding) has a number of unique advantages. It is a simple, rapid, facile, economic and quantitative process and has been intensely studied these years. $^{23-28}$ Wet-mechanochemical (also known as liquid-assisted grinding method, i.e., wet ball-milling (WB) here), could be considered as a combination of wet chemistry and mechanochemistry. Wet reaction media provide a homogenous 
liquid reaction environment and therefore bestow better molecular mobility and mass transport than that in solid-solid reaction conditions. ${ }^{29}$ When redox reactions are mechanically induced in the process by the high impact velocity of the balls in the mill, the morphology of the particles is manipulated by directional mechanical force, simultaneously creating chemical reaction points through the conversion of mechanical energy. Consequently, the products of redox reactions are "wet-welded" together. High frequency collisions in liquid media would be practical to direct the chemical reaction venues and particle anchoring spots, leading to the achievement of the uniform resultant materials. Thus it is particularly useful for mass production and for high performance LIBs.

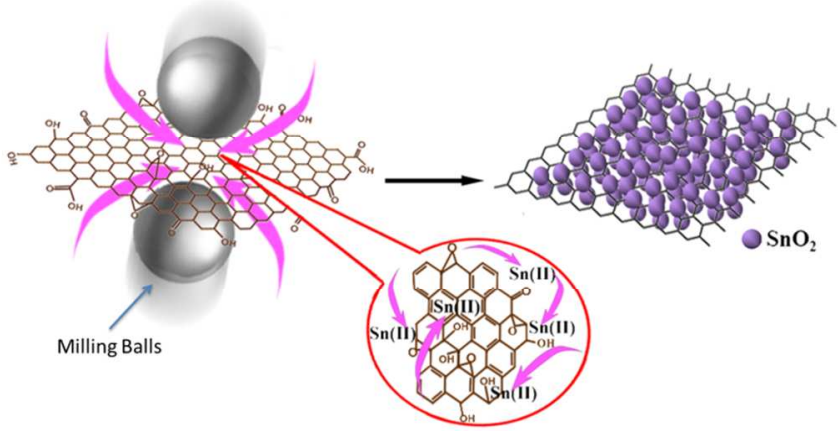

Fig 1. Schematic representation of the formation mechanism of the $\mathrm{SnO}_{2} @$ graphene nanocomposites in the WB process.

In this work, the WB method is applied to synthesize the $\mathrm{SnO}_{2} @$ graphene nanocomposites using $\mathrm{SnCl}_{2}$ and graphene oxide (GO) at room temperature in a one pot strategy. In the WB reaction, stannous chloride $\left(\mathrm{SnCl}_{2}\right)$ is firstly hydrolysed to $\mathrm{Sn}(\mathrm{OH}) \mathrm{Cl}$ as shown in reaction (3), and subsequently $\mathrm{Sn}(\mathrm{OH}) \mathrm{Cl}$ reduces $\mathrm{GO}$ to graphene under continues mechanical forces ${ }^{30-32}$ :

$\mathrm{SnCl}_{2}+\mathrm{H}_{2} \mathrm{O} \leftrightarrow \mathrm{Sn}(\mathrm{OH}) \mathrm{Cl}+\mathrm{HCl}$

$\mathrm{Sn}(\mathrm{OH}) \mathrm{Cl}+\mathrm{GO} \stackrel{\text { WB }}{\rightarrow} \mathrm{SnO}_{2} @$ graphene $+\mathrm{HCl}$

In liquid media, $\mathrm{Sn}(\mathrm{OH}) \mathrm{Cl}$ can be dispersed homogeneously. As shown in Fig 1, when the balls collide, the kinetic energy of the collision is utilized to overcome the activation energy barriers of the chemical reactions. Reduction of the GO is most likely to occur at the ball collision points which possess the highest energy converted from the powerful mechanical collision. Under this mechanism, the functional groups (such as hydroxyl, carbonyl, carboxylic and bridge oxygen) of the GO sheets are reduced by the $\mathrm{Sn}(\mathrm{OH}) \mathrm{Cl}$, producing graphene and $\mathrm{SnO}_{2}$ nanoparticles at those collision points. In fact, under constant collisions the produced $\mathrm{SnO}_{2}$ nanoparticles are immediately directed onto the "welding spots" of the two dimensional graphene sheets densely, leading to the formation of $\mathrm{SnO}_{2} @$ graphene nanocomposites (denoted as SG-WB). This is a very significant advantage in comparison with traditional thermal-induced reaction where the reaction could take place randomly without the directional guidance for the $\mathrm{SnO}_{2}$ nanoparticles to bond with the reaction sites.

\section{Experimental}

\section{Materials Preparation:}

The $\mathrm{SnO}_{2} @$ graphene samples were prepared by dissolving stannous chloride $\left(\mathrm{SnCl}_{2} \cdot 2 \mathrm{H}_{2} \mathrm{O}\right.$, Merck Pty. Ltd.) and graphene oxides (GO,
Tianjin Plannano Technology Co. Ltd.) in $10 \mathrm{~mL}$ high-purity deionized water (Millipore Corp., $18.2 \mathrm{M} \Omega \mathrm{cm}$ ). Samples prepared with different weight ratios of $\mathrm{SnCl}_{2} \cdot 2 \mathrm{H}_{2} \mathrm{O}$ and GO: (a) $45: 10$ (0.45g: 0.10g), (b) 15:10 (0.15g: 0.10g) and (c) 75:10 (0.75g: 0.10g), are denoted as SG-WB, SG-WB-15 and SG-WB-75, respectively. The mixture was added into a planetary zirconia ball miller $(50 \mathrm{~mL}$; QM-3SP04, Nanjing Nanda Instrument Plant; ball to powder weight ratio is 40:1, approximately) in air at the room temperature (ca. $23.0^{\circ} \mathrm{C}$ ) at a speed of $500 \mathrm{rpm}$ for $3 \mathrm{~h}$. The resultant solutions were centrifuged and washed with deionized water for three times and with ethanol for one time. The remaining solids were dried in a vacuum oven at $60^{\circ} \mathrm{C}$ for $12 \mathrm{~h}$.

In order to compare the effect of the proposed wet ball-milling with dry ball-milling and simple wet chemistry on the structure and performance of resultant products, several types of controlled samples are synthesized. In particular, $\mathrm{SnO}_{2}-\mathrm{WB}: 0.45 \mathrm{~g}$ of $\mathrm{SnCl}_{2} \cdot 2 \mathrm{H}_{2} \mathrm{O}$ was ball-milled under the identical experimental conditions of SG-WB sample in the absence of GO. SG-DB: $0.45 \mathrm{~g}$ of $\mathrm{SnCl}_{2} \cdot 2 \mathrm{H}_{2} \mathrm{O}$ and $0.10 \mathrm{~g} \mathrm{GO}$ were dry ball-milled under the same conditions; SG-W: $0.45 \mathrm{~g}$ of $\mathrm{SnCl}_{2} \cdot 2 \mathrm{H}_{2} \mathrm{O}$ and $0.10 \mathrm{~g}$ GO were dissolved in $10 \mathrm{~mL}$ water and stirred for $3 \mathrm{~h}$ (without ball-milling).

Commercial tin oxide powder $\left(\mathrm{SnO}_{2}\right.$, Nanostructured \& Amorphous Materials Inc.) is used without further purification.

\section{Materials Characterizations:}

The microstructure and morphology of materials were examined by scanning electron microscope (SEM, JSM-7001F) and transmission electron microscopy (TEM) (FEI Model Tecnai G20). Energydispersive X-ray spectroscopy (EDS) analysis and element mapping were obtained from JEOL JSM-6610. X-ray diffraction (XRD) was characterized (Model LabX-6000, Shimadzu, Japan) using $\mathrm{CuK} \alpha$ radiation at $40 \mathrm{kV}$ and $40 \mathrm{~mA}$ over the $2 \theta$ range of $10-80^{\circ}$. For Xray photoelectron spectroscopy (XPS, Kratos Axis ULTRA incorporating a $165 \mathrm{~mm}$ hemispherical electron energy analyzer) test, all binding energies were referenced to the $\mathrm{C} 1 s$ peak $(284.8 \mathrm{eV})$. Raman spectra were examined at room temperature by a Renishaw 100 system (Raman spectrometer using $514 \mathrm{~nm}$ Agraphenen green laser as light source). The thermogravimetric analysis (TGA) was performed on a TA instruments (series Q500) in air flow and at a heating rate of $5^{\circ} \mathrm{C} \mathrm{min}^{-1}$.

\section{Battery Assembling:}

Prepared active materials were mixed with 10 wt \% carbon black and $10 \mathrm{wt} \%$ polyvinylidene difluoride (PVDF, MW $\approx 534000$, Aldrich) in N-methyl-2-pyrrolidone (NMP, 99.5\%, Aldrich) solvent to form a homogeneous slurry, respectively. The resultant slurries were uniformly coated onto $\mathrm{Cu}$ foils with an area of $1 \mathrm{~cm}^{2}$. The weight of the electrode material is c.a. $1 \sim 2 \mathrm{mg}$. All the pasted $\mathrm{Cu}$ foils, i.e., the anodes, were dried in a vacuum oven at $60{ }^{\circ} \mathrm{C}$ for $12 \mathrm{~h}$ and then pressed by a double-roll compressor.CR2032 coin-type cells were assembled in an argon-filled M-Braun glove box. A porous polypropylene film was used as the separator, a lithium sheet as the counter electrode, and $1 \mathrm{M} \mathrm{LiPF}_{6}$ in a $1: 1(\mathrm{w} / \mathrm{w})$ mixture of ethylene carbonate (EC) and dimethyl carbonate (DMC) as the electrolyte. To measure the electrochemical capacity and cycle life of the working electrodes, the cells were galvanostatically charged and discharged using LANDCT2001A battery tester (Wuhan, PRC) in a voltage range from 0.01 to $2.5 \mathrm{~V} \mathrm{vs} \mathrm{Li} / \mathrm{Li}^{+}$. 
Cyclic voltammograms (CVs) were performed using a $\mathrm{CHI}$ 660D electrochemical workstation (CH Instrument, Shanghai, PRC). CVs were recorded between $2.5 \mathrm{~V}$ and $0.01 \mathrm{~V}$ at a scan rate of $0.1 \mathrm{mV} \mathrm{s}^{-1}$, using the composite as the working electrode and a lithium sheet as both counter electrode and reference electrode. Electrochemical impedance spectroscopy (EIS) was carried out with amplitude of $5 \mathrm{mV}$ over the frequency range from $100 \mathrm{kHz}$ to $0.01 \mathrm{~Hz}$.
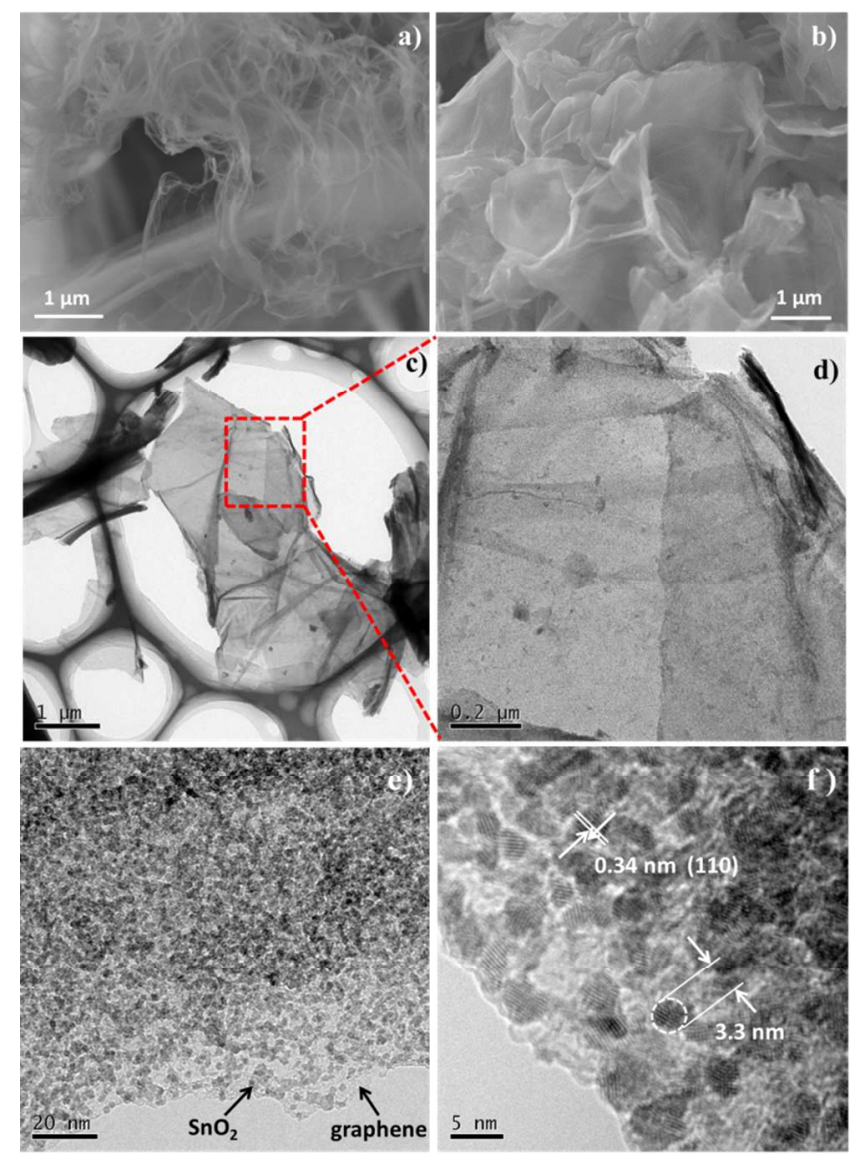

Fig 2. SEM images of GO (a), SG-WB (b); TEM images with different magnifications (c), (d), (e) and HRTEM image (f) of the SG-WB composite.

\section{Results and discussion}

The morphologies of the products produced by this WB process have been investigated by SEM. Fig 2a illustrates that GO has a typical extremely thin and semi-transparent graphene sheets structure. Without the addition of GO in the wet ball-milling process (sample $\mathrm{SnO}_{2}-\mathrm{WB}$ ), tin oxides particles with an average size distributed around $1 \mu \mathrm{m}$ were obtained, as shown in Fig S2a and b; some aggregation of these particles occurs under the constant ball milling process. For the SG-W sample, which was prepared from the wetchemistry without ball-milling, an uneven structure was obtained (Fig S2c). The sample is a physical mixture of $\mathrm{SnO}_{2}$ particles, graphene sheets, GO sheets, and SG-WB nanocomposites. Tin compounds rods (less than $10 \mu \mathrm{m}$ ) can be observed in the mixture (Fig S2d, the back-scattered electron analysis image). The formation of the mixture can be ascribed to the lack of the direction synthesis function of the mechanochemical process for the chemical reaction (4) and the particle anchoring process. Consequently, an abundance of tin oxides rods can be detected residing in the SG-W sample without anchoring to the graphene sheets. For the SG-DB sample, large bulky micron sized particles can be readily observed (in Fig S2e) due to the lack of disperse effect of the water. This is the typical morphology for dry ball-milling product.

In contrast, the SG-WB sample has uniform wrinkled-looking sheets, which are significantly thicker than the original GO sheets (Fig 2b and Fig S2f) due to the formation of a dense layer $\mathrm{SnO}_{2}$ nanoparticles evenly attached on the surface of graphene sheets. The sheets are in the same size with GO, suggesting that there are no structural damage to GO during the WB process. Moreover, no large rods or blocks (tin compounds aggregates and graphene aggregates) are observed, indicating that both the as-aforementioned aggregation of the $\mathrm{SnO}_{2}$ particles and restacking of graphene sheets are effectively prevented in the WB process.
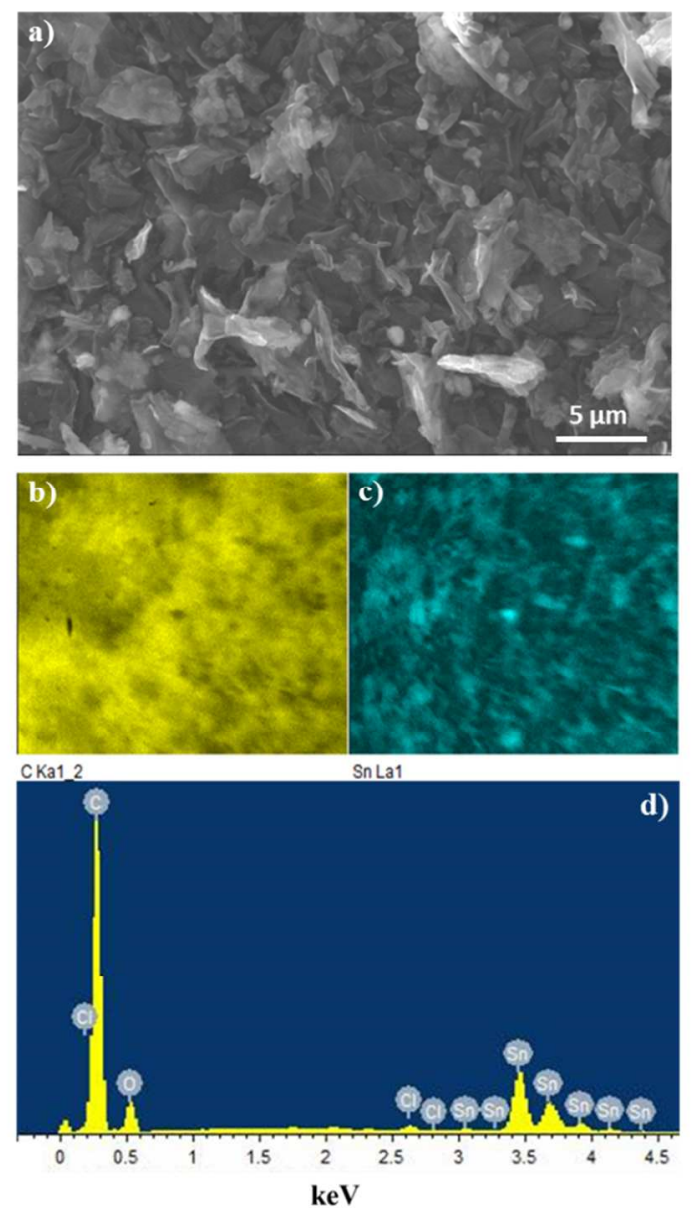

Fig 3. SEM image of the SG-WB (a) and the EDS elemental mappings spectra of $\mathrm{C} \mathrm{(b),} \mathrm{Sn} \mathrm{(c)} \mathrm{and} \mathrm{the} \mathrm{EDS} \mathrm{spectrum} \mathrm{(d)} \mathrm{of} \mathrm{the}$ SG-WB sample.

Fig $2 \mathrm{c}$ and $2 \mathrm{~d}$ illustrate the morphology of SG-WB sheets by TEM. The size of a single composites sheet is about several micrometres, in line with SEM observation. The $\mathrm{SnO}_{2}$ crystallites attached uniformly on graphene sheets can be further corroborated from high resolution TEM images (Fig 2e and 2f). $\mathrm{SnO}_{2}$ nanoparticles are bonded to graphene sheets densely and homogeneously according to the high directional vector forces during WB process. The average size of $\mathrm{SnO}_{2}$ nanoparticles is c.a. $3 \mathrm{~nm}$, which is a fascinating result for forming materials in this size level by the mechanochemical 
method. Moreover, the adjacent lattice fringe $d$-spacing of $0.34 \mathrm{~nm}$ can be ascribed to (110) planes of rutile $\mathrm{SnO}_{2}$.

EDS and elemental mapping (Fig 3) also confirm that the morphology change between $\mathrm{GO}$ and graphene sheets is due to $\mathrm{SnO}_{2}$ particles since $\mathrm{Sn}$ and $\mathrm{C}$ are distributed uniformly on the surface of graphene sheets which agrees with the TEM results.

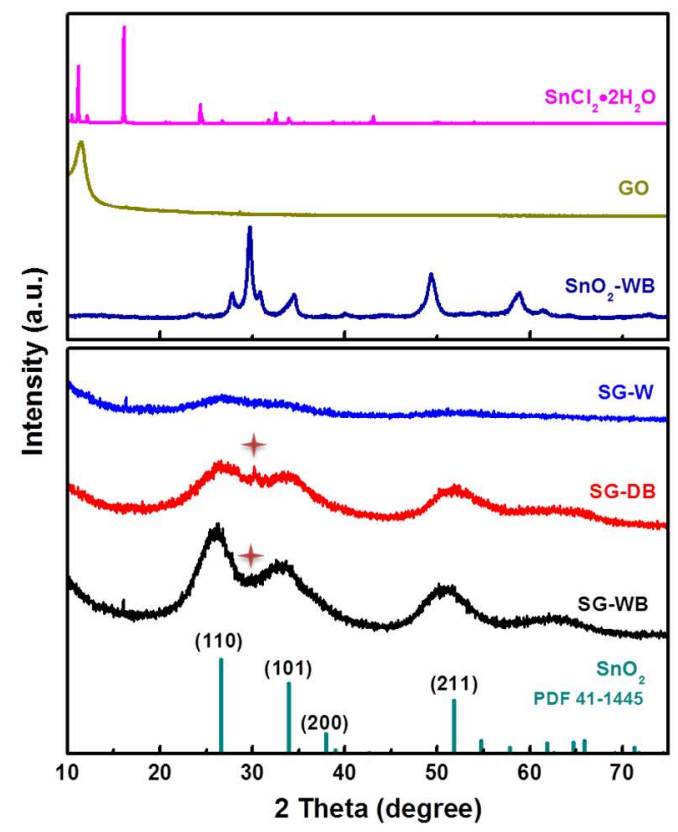

Fig 4. $\mathrm{XRD}$ patterns of the $\mathrm{SnCl}_{2} \cdot 2 \mathrm{H}_{2} \mathrm{O}, \mathrm{GO}, \mathrm{SnO}_{2}-\mathrm{WB}, \mathrm{SG}-\mathrm{W}, \mathrm{SG}-$ DB and SG-WB samples.

XRD patterns confirm the above conclusion. Fig 4 shows that there is only one peak $\left(2 \theta=11.49^{\circ}\right)$ of GO pattern, and according to Bragg's equation $(2 d \sin \theta=n \lambda)$, the distance $(d)$ between GO layers is $0.77 \mathrm{~nm}$ which is much larger than graphite $(\mathrm{d}(200)=0.336 \mathrm{~nm})$ due to carbon-oxygen bond and oxygen-containing functional groups between GO layers. For $\mathrm{SnO}_{2}-\mathrm{WB}$, there are no $\mathrm{GO}$ added as the reactant, thus no typical rutile $\mathrm{SnO}_{2}$ indexed peak is observed but only a mixture of tin-oxides at various tin valence states. Before reaction, peaks for $\mathrm{SnCl}_{2} \cdot 2 \mathrm{H}_{2} \mathrm{O}$ can be clearly observed in the XRD pattern. After the WB process, the typical XRD peaks of $\mathrm{SnCl}_{2} \cdot 2 \mathrm{H}_{2} \mathrm{O}$ disappeared, instead, a rutile $\mathrm{SnO}_{2}$ crystal pattern (JCPDS No.41-1445, space group P42/mnm, $d(110)=0.335 \mathrm{~nm}$ in agreement with the HRTEM result) and a broad $\mathrm{SnO}$ peak $(2 \theta=$ $30.1^{\circ}$, JCPDS No. 07-0195) were observed. This pattern suggests that the reactions (3) and (4) occurred and produced the $\mathrm{SnO}_{2}$ nanoparticles in the WB process without the need for thermal treatment in traditional process. The SG-WB sample shows broad diffraction peaks, which could be contributed by the small size of $\mathrm{SnO}_{2}$ particles. The particle size was calculated by Scherrer formula $(D=K \lambda / B \cos \theta)$ as c.a. $3 \mathrm{~nm}$, which is consistent with the HRTEM measurements. SG-DB shows weaker $\mathrm{SnO}_{2}$ and $\mathrm{SnO}$ patterns at the similar $2 \theta$. This reveals that without aqueous reaction media, $\mathrm{SnO}_{2}$ still can be formed by mechanochemical reaction, but the resultant crystallinity is not as good as the wet ball-milled sample. The XRD peaks of SG-W are broad and cannot be distinguished easily, because the resultant $\mathrm{SnO}_{2}$ products from the wet-chemistry process are mainly amorphous, which need further thermal treatment before use.
XPS is a useful tool for identifying the changes of carbon-oxygen bonds and oxygen-containing functional groups at surface of materials. In this case, it could provide evidence of the reduction of $\mathrm{GO}$ and the formation of $\mathrm{SnO}_{2}$ during the wet-ball milling process.
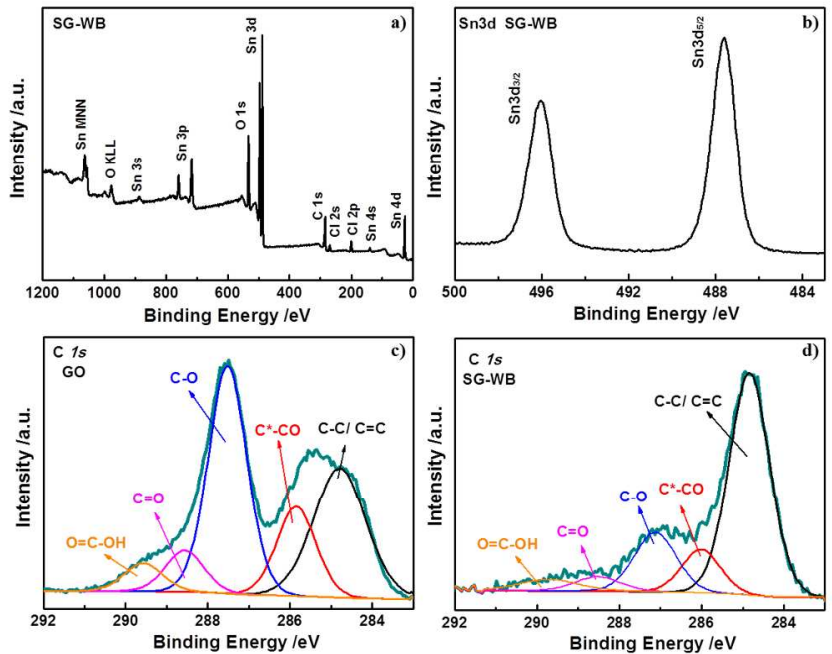

Fig 5. XPS spectra images: XPS survey scan of SG-WB (a); $\mathrm{Sn} 3 d$ XPS spectra of SG-WB (b); C1s XPS spectra of GO (c); C1s XPS spectra of SG-WB (d).

The XPS survey spectra of the SG-WB sample (Fig 5a) shows the presence of $\mathrm{O}, \mathrm{Sn}, \mathrm{C}$ and $\mathrm{Cl}$ (trace residue of the reactant $\mathrm{SnCl}_{2}$ ), which is consistent with the EDS findings. Fig. 5b shows the $\mathrm{Sn} 3 d$ spectrum of SG-WB has two peaks at $487.6 \mathrm{eV}$ and $496.1 \mathrm{eV}$, which are attributed to $\operatorname{Sn} 3 d_{5 / 2}$ and $\operatorname{Sn} 3 d_{3 / 2}$, respectively, confirming the formation of $\mathrm{SnO}_{2}$ nanoparticles. ${ }^{33-35}$ Peaks of $\mathrm{C}-\mathrm{C} / \mathrm{C}=\mathrm{C}\left(s p^{2} \mathrm{C}\right)$, $\mathrm{C}^{*}-\mathrm{CO}, \mathrm{C}-\mathrm{O}, \mathrm{C}=\mathrm{O}$ and $\mathrm{O}=\mathrm{C}-\mathrm{OH}$ groups can be divided from $\mathrm{C} 1 \mathrm{~s}$ spectrums of GO, which centered at $284.8 \mathrm{eV}, 285.8 \mathrm{eV}, 287.5 \mathrm{eV}$, $288.6 \mathrm{eV}$ and $289.6 \mathrm{eV}$, respectively (Fig 5c). After the WB process, the intensities of the divided spectroscopic components corresponding to the oxygen-containing functional groups decline due to the reduction reaction (Eq. 4). It can be concluded that the GO is reduced and the $\mathrm{SnO}_{2}$ and graphene are formed.
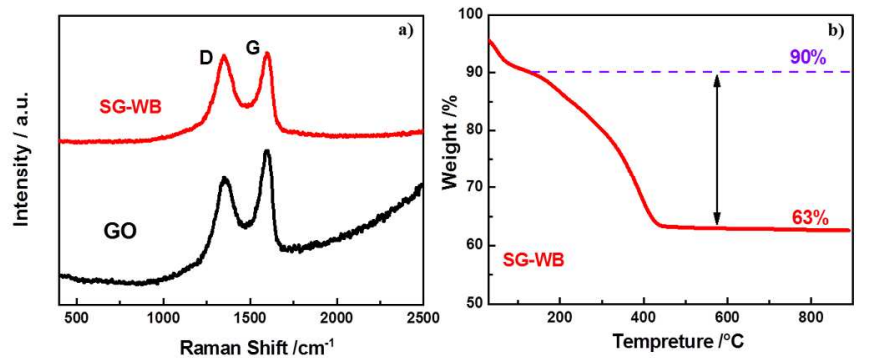

Fig 6. Raman spectra of the GO and SG-WB (a); TGA curve of SGWB (b).

Notable changes of the GO occurred during the WB process are displayed in their Raman spectroscopy spectra as shown in Fig 6a. The peaks located at $1350 \mathrm{~cm}^{-1}$ and $1601 \mathrm{~cm}^{-1}$ are both observed, representing the $\mathrm{D}$ band and the $\mathrm{G}$ band, respectively. The $\mathrm{G}$ band is related to the presence of isolated double bonds while the D band is linked with the disruption of the symmetrical hexagonal graphitic lattice. Therefore, the relative intensities ratio of the $D$ to $G$ bands $\left(I_{D} / I_{G}\right)$ can be considered as a result of the reduction in the $s p^{2}$ domain size. An increased $I_{D} / I_{G}(1.70)$ ratio of SG-WB is obtained after the WB reaction in comparison with GO (1.23), which indicates 
a decrease in the average size of the $s p^{2}$ domains upon the reduction of $\mathrm{GO},{ }^{36-38}$ and the successful attachment of $\mathrm{SnO}_{2}$ nano particles on graphene sheets.

To investigate the mass percentage of $\mathrm{SnO}_{2}$ of SG-WB composites, SG-WB was characterized by TGA, which is shown in Fig 6b. The weight loss before $120^{\circ} \mathrm{C}$ is attributed to the evaporation of water $\left(10 \%\right.$ of water content) and the weight loss between $120{ }^{\circ} \mathrm{C}$ and 450 ${ }^{\circ} \mathrm{C}$ is due to the oxidation of graphene in air, emitting $\mathrm{CO}_{2}$. Therefore, the weight percentage of $\mathrm{SnO}_{2}$ of the composites can be estimated using $63 \%$ from $90 \%$ as the whole weight of SG-WB. The final percentage is c.a. $70 \%$.

The electrochemical performance of SG-WB were tested by CV and galvanostatic charge/discharge measurements, in a potential window

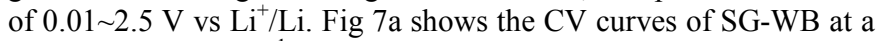
scan rate of $0.1 \mathrm{mV} \mathrm{s}^{-1}$, in which two cathodic peaks can be observed from the first cycle at $0.6 \mathrm{~V} \sim 1.0 \mathrm{~V}$ and $0.01 \mathrm{~V}$ which are generally consistent with the typical $\mathrm{SnO}_{2}$-based anodes. ${ }^{12,39}$ The difference between the first and subsequent cycles (broad cathodic peak between $0.6 \mathrm{~V}$ and $1.0 \mathrm{~V}$ ) is mainly due to the formation of the solid electrolyte interface (SEI) layer, the partial reversibility of the reduction of $\mathrm{SnO}_{2}$ to $\mathrm{Sn}$, and the formation of $\mathrm{Li}_{2} \mathrm{O},{ }^{40}$ as shown in reaction (1). The CVs of the second and third cycles are almost overlapped, indicating that the performance stabilizes rapidly and the electrochemical process is mostly reversible. There are two characteristic redox pairs at potentials of $(0.01,0.6 \mathrm{~V})$ and $(1.0,1.3$ $\mathrm{V})$, respectively. The first redox pair is corresponding to the reversible formation of $\mathrm{Li}_{\mathrm{x}} \mathrm{Sn}$ alloys $(0 \leq \mathrm{x} \leq 4.4$, as indicated in the reaction (2), and the second one can be ascribed to the reaction in Reaction (1) and the SEI film. ${ }^{41-43}$

Fig $7 \mathrm{~b}$ shows the first, second, third and the $50^{\text {th }}$ cycle galvanostatic charge/discharge voltage profiles for SG-WB at a current density $100 \mathrm{~mA} \mathrm{~g}{ }^{-1}$. Typically for $\mathrm{SnO}_{2}$ anodes, there are slopes in two regions in the first discharge process, ${ }^{35}$ owing to the combination by SEI film formation and $\mathrm{SnO}_{2}$ reduction to $\mathrm{Sn}$. The curves of the second and third cycle are also agreeing well with $\mathrm{CV}$ curves for the two characteristic redox pairs. The shape of the $50^{\text {th }}$ cycle curve has barely changed, which demonstrates a good reversibility of the SGWB sample. Compared with the first cycles of $\mathrm{SnO}_{2}-\mathrm{WB}$ and commercial $\mathrm{SnO}_{2}$ electrodes (Fig $\mathrm{S} 3 \mathrm{a}$ and b), a much higher coulombic efficiency is obtained from the SG-WB electrode; moreover, higher reversible charge/discharge capacities are gained from the second cycle as well. This probably can be attributed to the following factors: the improved conductivity due to the incorporation of graphene; the achievement of the nano-size of $\mathrm{SnO}_{2}$ particles; the strong bonding between the $\mathrm{SnO}_{2}$ nanoparticles. Graphene sheets and resultant layer structure of the SG-WB sample are beneficial in tolerating strain, volume variation and prevent the aggregation of $\mathrm{SnO}_{2}$ and $\mathrm{Sn}$ during charge and discharge process. ${ }^{35}$

Fig 7c shows the cycling performance of the SG-WB at a current density of $100 \mathrm{~mA} \mathrm{~g}^{-1}$ for 100 cycles. The initial discharge capacity is $1445 \mathrm{mAh} \mathrm{g}^{-1}$, which is owing to the combination of the reactions (1) and (2), and the formation of stable SEI. Discharge capacity of the second cycle is $773.6 \mathrm{mAh} \mathrm{g}^{-1}$ and the loss of capacity compared with the first cycle is due to the partly irreversible reaction (1). The specific capacity remains at $620 \mathrm{mAh} \mathrm{g}^{-1}$ after 100 cycles, and the coulombic efficiency of SG-WB stays c.a. $100 \%$ in the whole galvanostatic charge/discharge measurement, indicating high capacity and excellent stability. In order to investigate the electrochemical performance further, rate charge/discharge characterizations for SG-WB at different currents densities are carried out and the charge/discharge capacities are shown in Fig 7d. Reversible and stable capacity can be clearly observed. It is remarkable that the capacity remains $220 \mathrm{mAh} \mathrm{g}^{-1}$ at a current density of $1500 \mathrm{~mA} \mathrm{~g}^{-1}$. The specific capacity maintains at $640 \mathrm{mAh}$ $\mathrm{g}^{-1}$ from the 50th cycle for SG-WB anode when the current density returns to $100 \mathrm{~mA} \mathrm{~g}^{-1}$ after the large current charge/discharge processes.
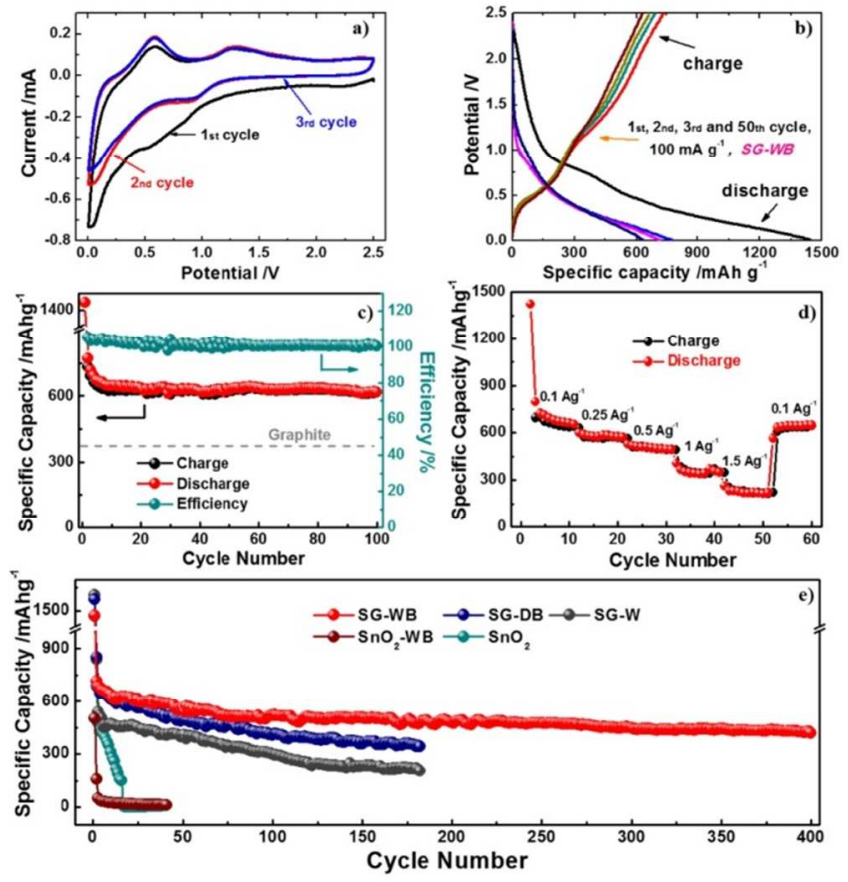

Fig 7. CV curves of the first three cycles of the SG-WB electrode (a), the $1^{\text {st }}, 2^{\text {nd }} 3^{\text {rd }}$ and $50^{\text {th }}$ cycle charge-discharge profiles for SG$\mathrm{WB}$ at a current density of $100 \mathrm{~mA} \mathrm{~g}^{-1}$ in the voltage range $0.01 \sim 2.5$ $\mathrm{V}$ (b); The charge/discharge capacities and the coulombic efficiency of SG-WB at $100 \mathrm{~mA} \mathrm{~g}^{-1}$ (c), the rate charge/discharge capability for SG-WB (d); and discharge capacities of $\mathrm{SnO}_{2}-\mathrm{WB}$, commercial $\mathrm{SnO}_{2}$, SG-DB, SG-W and SG-WB electrodes, at $400 \mathrm{~mA} \mathrm{~g}{ }^{-1}$, respectively (e).

Fig 7e illustrates long cycle life cycling tests at a current density of $400 \mathrm{~mA} \mathrm{~g}^{-1}$. Without the graphene structure skeleton, dramatically dropped capacities during the first 50 cycles could be observed for both the $\mathrm{SnO}_{2}$-WB and the commercial $\mathrm{SnO}_{2}$ samples, owing to the collapse of the electrodes materials from the volume variation during charge/discharge process. Moreover, the conductivities of both $\mathrm{SnO}_{2}$-WB and commercial $\mathrm{SnO}_{2}$ are extremely poor due to the lack of graphene. For SG-DB electrode, according to XRD results, $\mathrm{SnO}_{2}$ has also been formed by the mechanochemical method, thus it shows a similar capacity as SG-WB for the first 30 cycles. However, without liquid reaction media, the large bulk morphology of the product and the lack of homogeneity lead to less tolerance for the volume changing of $\mathrm{Sn}$ during the charge/discharge process. Therefore, the electrode materials collapse, and the specific capacity of the SG-DB sample decreases to $343 \mathrm{mAh} \mathrm{g}^{-1}$ after 180 cycles. The specific capacity of the SG-W is significantly lower than that of the SG-WB and SG-DB samples. It goes down to $217 \mathrm{mAh} \mathrm{g}^{-1}$ at its $180^{\text {th }}$ cycle. This fast decay is due to the poor connection between the amorphous tin oxides and the graphene sheets. For SG-WB electrode, significantly cycling life performance could be obtained. It retains over $500 \mathrm{mAh} \mathrm{g}^{-1}$ for the $150^{\text {th }}$ cycle and after 400 cycles, the capacity is still over $420 \mathrm{mAh} \mathrm{g}^{-1}$, which is much higher than the theoretical capacity of commercial graphite electrode. 
To further study the electrochemical property of the as-prepared nanocomposites, EIS measurements were conducted. The Nyquist plots obtained after 50 charge/discharge cycles for SG-WB, SG-DB and SG-W are shown in Fig S4. The shapes of the plots of SG-DB and SG-W are similar with depressed semicircles in high-middle frequency region, displaying the charge transfer resistance $\left(R_{c t}\right)$. The two depressed semicircles of high and middle frequency region for SG-WB are attributed to SEI film and $R_{c t}$, indicating a good SEI film for SG-WB and a smaller $R_{c t}$ than that of SG-DB and SG-W. ${ }^{36}$ The differences of the electrodes $R_{c t}$ could be owing to the uneven bulk morphology for SG-DB and the poor combination of the components for SG-W. After charge/discharge for 50 cycles, the collapse of electrode materials for SG-DB and SG-W causing by $\mathrm{Sn}$ volume change may also contribute to their larger $R_{c t}$.
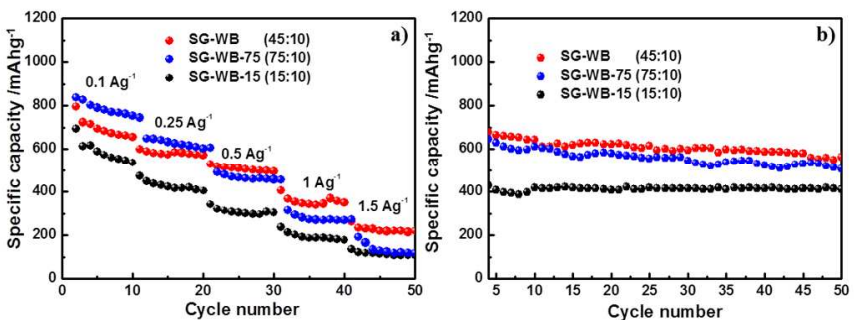

Fig 8. The rate capabilities of the samples with different ratios of $\mathrm{SnCl}_{2} \cdot 2 \mathrm{H}_{2} \mathrm{O}$ and $\mathrm{GO}$ at various discharge rates (a); the specific capacity of the samples at a constant discharge rate of $400 \mathrm{~mA} \mathrm{~g}^{-1}$ (b).

The effects of the ratio of raw materials $\left(\mathrm{SnCl}_{2} \cdot 2 \mathrm{H}_{2} \mathrm{O}\right.$ and $\left.\mathrm{GO}\right)$ on the rate performance are also investigated. The SG-WB, SG-WB-75 and SG-WB-15 samples were prepared with $\mathrm{SnCl}_{2} \cdot 2 \mathrm{H}_{2} \mathrm{O}$ : GO ratios of $45: 10,75: 10$ and 15:10, respectively. Fig 8 illustrates the discharge capacities of the samples at different discharge current densities from 100 to $1500 \mathrm{~mA} \mathrm{~g}^{-1}$, respectively. At low current densities $\left(100 \sim 250 \mathrm{~mA} \mathrm{~g}^{-1}\right)$, The SG-WB-75 sample delivers the highest specific capacity because it contains the highest weight percentage of $\mathrm{SnO}_{2}$ in the electrode while SG-WB-15 has the lowest capacity due to the lowest $\mathrm{SnO}_{2}$ content. In strong contrast, at high current densities $\left(500 \sim 1500 \mathrm{~mA} \mathrm{~g}^{-1}\right)$, the SG-WB sample demonstrates the highest capability in Fig $8 \mathrm{a}$ as well as the best cycling stability (see Fig 8b) for 50 cycles at $400 \mathrm{~mA} \mathrm{~g}^{-1}$. This should be also attributed to the resilient structure of the resultant composite.

\section{Conclusions}

In summary, the one-step WB method was successfully used to prepare $\mathrm{SnO}_{2} @$ graphene nanocomposites using GO and $\mathrm{SnCl}_{2}$ as precursors in this work. Due to the directional effect of the WB method, introduction of the aqueous reaction media and the constant powerful collisions between the reactants, GO was thoroughly reduced to graphene while $\mathrm{SnCl}_{2}$ was oxidised in-situ to $\mathrm{SnO}_{2}$ nanoparticles that are strongly "welded" on the graphene sheets at the ball-colliding points during the reaction, resulting in uniform and resilient nanocomposites. The composites present a superior electrochemical performance in terms of rate capacity and cycle life as anode material for LIBs. This method could be further extended for large scale production of a series of metal oxides@graphene composites or other materials for practical applications in energy storage and conversion fields.

\section{Acknowledgements}

We acknowledged the support by the Australia Research Council Discovery Project and technical assistance by the Australian Microscopy \& Microanalysis Research Facility (AMMRF) at the Centre for Microscopy and Microanalysis (CMM), the University of Queensland.

\section{Notes and references}

${ }^{a}$ Centre for Clean Environment and Energy, Environmental Futures Research Institute, Griffith School of Environment, Gold Coast Campus, Griffith University, Queensland 4222, Australia

${ }^{b}$ Discipline of Nanotechnology and Molecular Science, Queensland University of Technology, GPO Box 2434, Brisbane, Queensland 4001, Australia

*To whom correspondence should be addressed.

E-mail: s.zhang@griffith.edu.au

A/Professor Shanqing Zhang

Electronic Supplementary Information (ESI) available: further characterizations of SEM, TEM and electrochemical tests. See DOI: $10.1039 / \mathrm{b} 000000 \mathrm{x} /$

1. J. B. Goodenough and K. S. Park, J. Am. Chem. Soc., 2013, 135, 1167.

2. M. Ling, J. Qiu, S. Li, G. Liu and S. Zhang, J. Mater. Chem. A, 2013, 1, 11543 .

3. M. V. Reddy, G. V. Subba Rao and B. V. Chowdari, Chemical reviews, 2013, 113, 5364.

4. J. Qiu, S. Zhang and H. Zhao, Sens. Actuators, B, 2011, 160, 875.

5. Y. Tang, D. Wu, S. Chen, F. Zhang, J. Jia and X. Feng, Energy Environ. Sci., 2013, 6, 2447.

6. D. Wang, X. Li, J. Wang, J. Yang, D. Geng, R. Li, M. Cai, T.-K. Sham and X. Sun, J. Phys. Chem. C, 2012, 116, 22149.

7. J. S. Chen and X. W. Lou, Small, 2013, 9, 1877.

8. C. Zhang, X. Peng, Z. Guo, C. Cai, Z. Chen, D. Wexler, S. Li and H. Liu, Carbon, 2012, 50, 1897.

9. J. Li, Y. Zhao, N. Wang and L. Guan, Chem. Commun. (Camb), 2011, 47, 5238.

10. X. Zhou, L. J. Wan and Y. G. Guo, Adv. Mater., 2013, 25, 2152.

11. X. Li, X. Meng, J. Liu, D. Geng, Y. Zhang, M. N. Banis, Y. Li, J. Yang, R. Li, X. Sun, M. Cai and M. W. Verbrugge, Adv. Funct. Mater., 2012, 22, 1647.

12. F. Han, W.-C. Li, M.-R. Li and A.-H. Lu, J. Mater. Chem., 2012, 22 , 9645.

13. K. Shiva, H. B. Rajendra, K. S. Subrahmanyam, A. J. Bhattacharyya and C. N. Rao, Chem. Eur. J., 2012, 18, 4489.

14. X. Zhou, Y.-X. Yin, L.-J. Wan and Y.-G. Guo, J. Mater. Chem., 2012, 22, 17456.

15. B. Li, H. Cao, J. Zhang, M. Qu, F. Lian and X. Kong, J. Mater. Chem., 2012, 22, 2851.

16. Y.-H. Jin, K.-M. Min, S.-D. Seo, H.-W. Shim and D.-W. Kim, J. Phys. Chem. C, 2011, 115, 22062.

17. D. Wang, J. Yang, X. Li, D. Geng, R. Li, M. Cai, T.-K. Sham and X. Sun, Energy Environ. Sci., 2013, 6, 2900.

18. Z. Chen, M. Zhou, Y. Cao, X. Ai, H. Yang and J. Liu, Adv. Energy Mater., 2012, 2, 95. 
19. J. Lin, Z. Peng, C. Xiang, G. Ruan, Z. Yan, D. Natelson and J. M. Tour, ACS Nano, 2013, 7, 6001.

20. B. Zhao, G. Zhang, J. Song, Y. Jiang, H. Zhuang, P. Liu and T. Fang, Electrochim. Acta, 2011, 56, 7340.

21. Y. Li, X. Lv, J. Lu and J. Li, J. Phys. Chem. C 2010, 114, 21770.

22. S. Xin, Y.-G. Guo and L.-J. Wan, Acc. Chem. Res., 2012, 45, 1759.

23. S. L. James, C. J. Adams, C. Bolm, D. Braga, P. Collier, T. Friscic, F. Grepioni, K. D. Harris, G. Hyett, W. Jones, A. Krebs, J. Mack, L. Maini, A. G. Orpen, I. P. Parkin, W. C. Shearouse, J. W. Steed and D. C. Waddell, Chemical Society reviews, 2012, 41, 413.

24. D. Braga, L. Maini and F. Grepioni, Chemical Society reviews, 2013, 42, 7638 .

25. M. C. Stan, R. Klöpsch, A. Bhaskar, J. Li, S. Passerini and M. Winter, Adv. Energy Mater., 2013, 3, 231.

26. S. L. James and T. Friscic, Chem. Commun. (Camb), 2013, 49, 5349.

27. C. Lai, Z. Wu, Y. Zhu, Q. Wu, L. Li and C. Wang, J. Power Sources, 2013, 226, 71.

28. F. Ye, B. Zhao, R. Ran and Z. Shao, Chem. Eur. J., 2014, n/a.

29. G. A. Bowmaker, Chem. Commun. (Camb), 2013, 49, 334.

30. J. D. Donaldson, W. Moser and W. B. Simpson, J. Chem. Soc. (Resumed), 1963, 1727.

31. H.-T. Fang, X. Sun, L.-H. Qian, D.-W. Wang, F. Li, Y. Chu, F.-P. Wang and H.-M. Cheng, J. Phys. Chem. C, 2008, 112, 5790.

32. H. Zheng, C.-D. Gu, X.-L. Wang and J.-P. Tu, J. Nanopart. Res., 2014, 16, 1 .

33. H. Seema, K. Christian Kemp, V. Chandra and K. S. Kim, Nanotechnology, 2012, 23, 355705.

34. F. Li, J. Song, H. Yang, S. Gan, Q. Zhang, D. Han, A. Ivaska and L. Niu, Nanotechnology, 2009, 20, 455602.

35. S. Yang, W. Yue, J. Zhu, Y. Ren and X. Yang, Adv. Funct. Mater., 2013, 23, 3570.

36. C. Zhong, J. Wang, Z. Chen and H. Liu, J. Phys. Chem. C, 2011, 115, 25115.

37. Y.-H. Hwang, E. G. Bae, K.-S. Sohn, S. Shim, X. Song, M. S. Lah and M. Pyo, J. Power Sources, 2013, 240, 683.

38. J. Liang, W. Wei, D. Zhong, Q. Yang, L. Li and L. Guo, ACS Appl. Mater. Interfaces, 2012, 4, 454.

39. L. Noerochim, J.-Z. Wang, S.-L. Chou, D. Wexler and H.-K. Liu, Carbon, 2012, 50, 1289.

40. P. Wu, N. Du, H. Zhang, C. Zhai and D. Yang, ACS Appl. Mater. Interfaces, 2011, 3, 1946.

41. S. Ding, D. Luan, F. Y. Boey, J. S. Chen and X. W. Lou, Chem. Commun. (Camb), 2011, 47, 7155.

42. T. Chen, L. Pan, X. Liu, K. Yu and Z. Sun, RSC Adv., 2012, 2, 11719.

43. M. Zhang, D. Lei, Z. Du, X. Yin, L. Chen, Q. Li, Y. Wang and T. Wang, J. Mater. Chem., 2011, 21, 1673. 
Colour graphic:

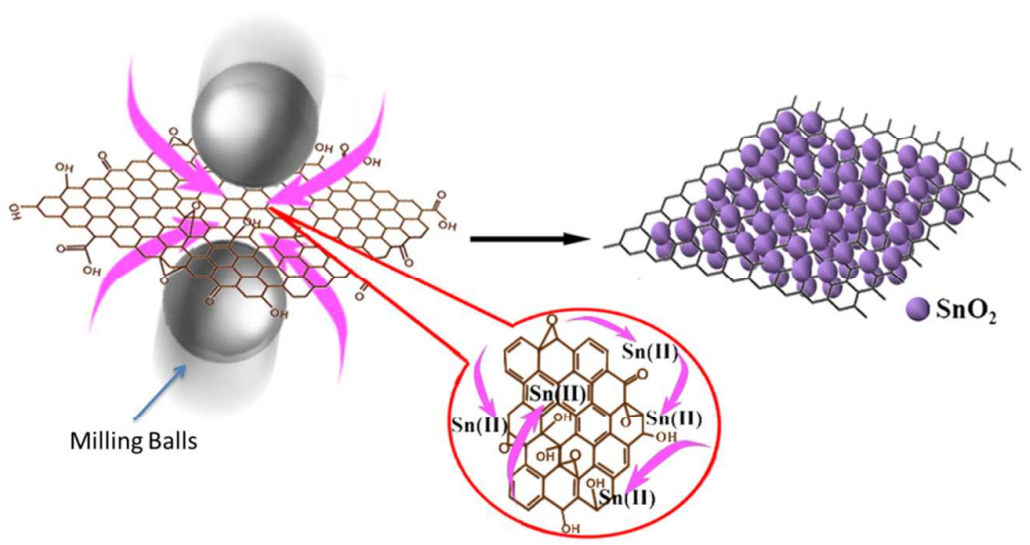

Text: $\mathrm{SnO}_{2} @$ graphene nano-composites with excellent lithium ion battery performance are successfully prepared by a one-step simple and up-scalable wet-mechanochemical method. 


\section{Journal of \\ Materials Chemistry A}

Accepted Manuscript

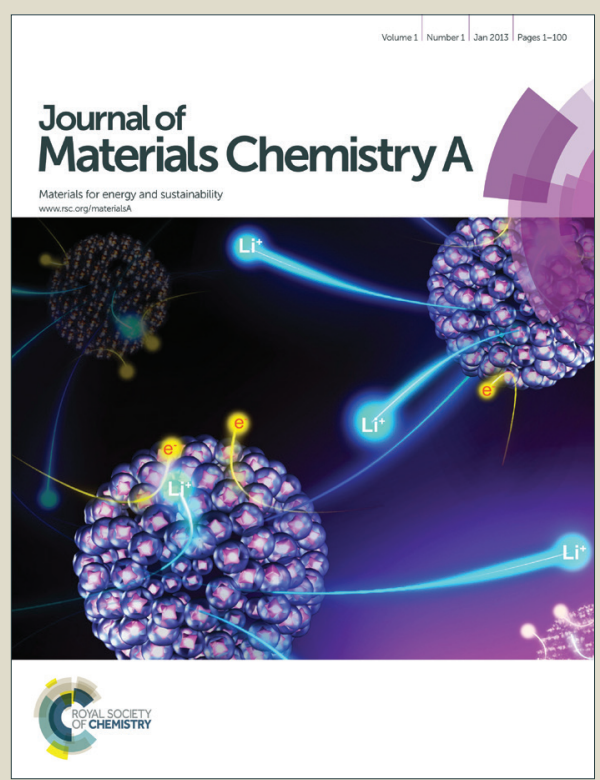

This is an Accepted Manuscript, which has been through the Royal Society of Chemistry peer review process and has been accepted for publication.

Accepted Manuscripts are published online shortly after acceptance, before technical editing, formatting and proof reading. Using this free service, authors can make their results available to the community, in citable form, before we publish the edited article. We will replace this Accepted Manuscript with the edited and formatted Advance Article as soon as it is available.

You can find more information about Accepted Manuscripts in the Information for Authors.

Please note that technical editing may introduce minor changes to the text and/or graphics, which may alter content. The journal's standard Terms \& Conditions and the Ethical guidelines still apply. In no event shall the Royal Society of Chemistry be held responsible for any errors or omissions in this Accepted Manuscript or any consequences arising from the use of any information it contains. 